21.1

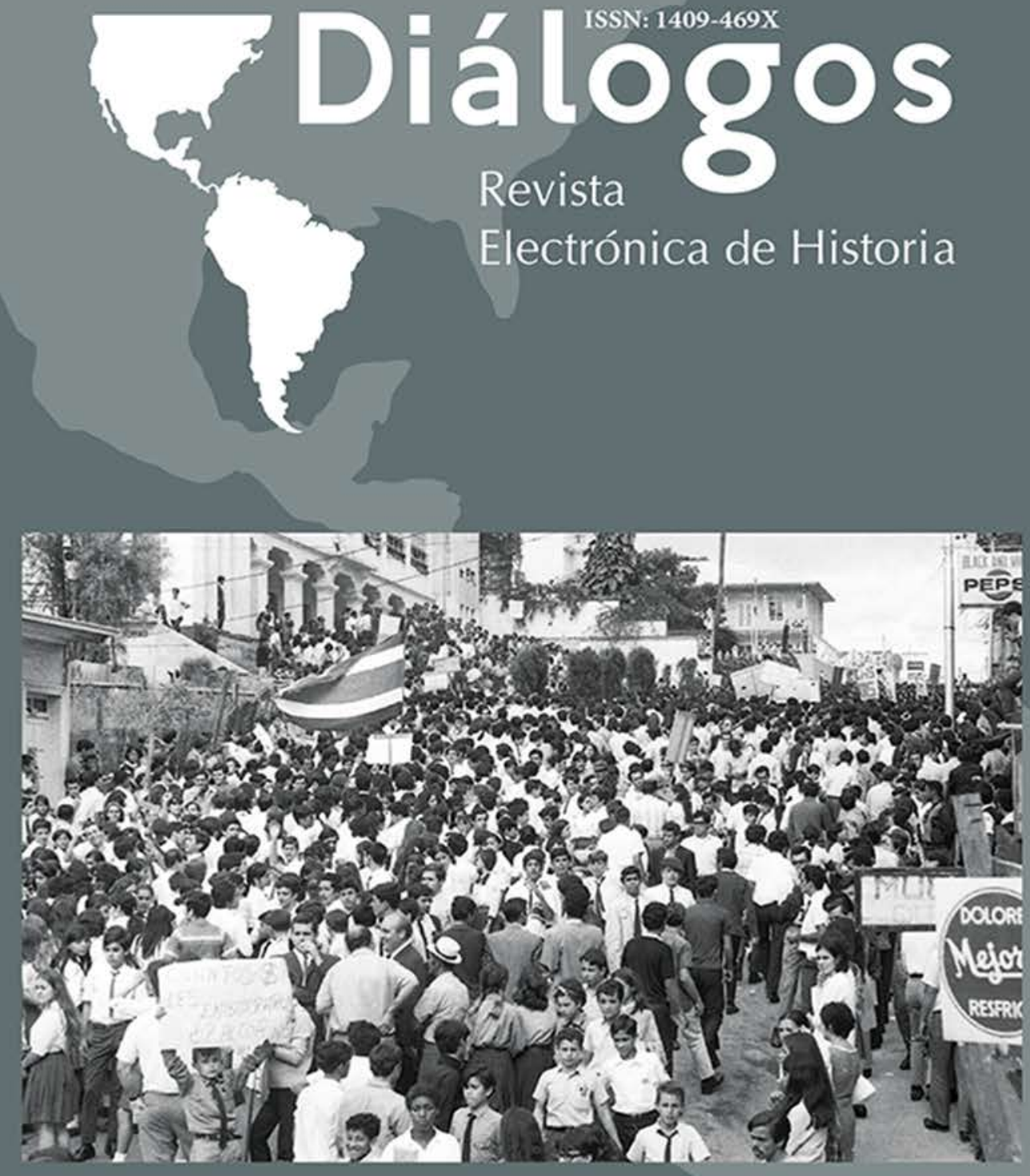

Centro de Investigaciones Históricas de América Central. Universidad de Costa Rica

\title{
Enero-junio 2020
}

url: http://revistas.ucr.ac.cr/index.php/dialogos/index

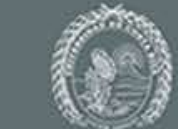

UNIVERSIDADDE

COSTARICA

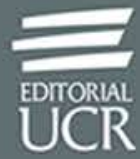




\title{
LA REPERCUSIÓN DE LA DESIGUALDAD Y LA EXCLUSIÓN EN EL CONFLICTO POLÍTICO DE NICARAGUA DE LA INDEPENDENCIA HASTA INICIOS DEL SIGLO XX
}

\author{
José Abelardo Baldizón
}

\begin{abstract}
Resumen
En Nicaragua, desde la independencia hasta principios del siglo XX, prevaleció la violencia en el conflicto político. Esto se debió a la incapacidad de las facciones en guerra para aceptar el derecho del adversario a convertirse en el gobierno del país, lo cual sumió al país en una dinámica de exclusión mutua y de constantes guerras civiles. Los factores clave para generar esta dinámica fueron: la estratificación social, el clientelismo político y el personalismo. Todos ellos producían un acceso desigual y excluyente al sistema político. La estratificación social se basaba en una concepción jerárquica del orden social que provocaba una profunda desigualdad en la distribución de la riqueza y en la capacidad de participar en la política. En el sistema político nicaragüense, esta desigualdad se reprodujo en forma de redes jerárquicas de clientes que luchan entre sí para controlar el Estado. Al mismo tiempo, las personas más cercanas a la cúspide de la jerarquía tenían mayores posibilidades de influir en el proceso de toma de decisiones políticas. Como resultado, la inclusión/exclusión en el sistema político fue regulada, en primer lugar, por la posición que ocupaba en la jerarquía social y política que tenía una persona y, en segundo lugar, por la cercanía de sus vínculos con los miembros del campo político que controlaba el aparato estatal.
\end{abstract}

Palabras clave: sistemas sociales, estratificación social, diferenciación social, sistema político, guerra civil. 


\title{
THE IMPACT OF INEQUALITY AND EXCLUSION IN NICARAGUA'S POLITICAL CONFLICT FROM ITS INDEPENDENCE UNTIL THE BEGINNING OF THE 20TH CENTURY
}

\begin{abstract}
In Nicaragua, from the Independence until the beginning of the 20th century, the political conflict was marked by violence. This resulted from the inability of the warring factions to accept the right of the adversary of becoming the country's government. This plunged the country into a dynamic of mutual exclusion and constant civil wars. The key factors in generating this dynamic were: social stratification, political clientelism, and personalism. All of them produced an unequal and excluding access to the political system. Social stratification was based on a hierarchical conception of the social order that caused a deep inequality in the distribution of wealth and the ability to participate in politics. In the Nicaraguan political system, this inequality was reproduced in the form of hierarchical client networks that struggle against each other to control the State. At the same time, those closest to the top of the hierarchy had greater possibilities to influence the political decision-making process. As a result, inclusion/exclusion in the political system was regulated, first, by the position in the social and political hierarchy a person had and, second, by the closeness of his ties with the members of the political camp that controlled the state apparatus.
\end{abstract}

Keywords: social systems, social stratification, social differentiation, political system, civil war. 
A lo largo de su historia, Nicaragua ha sido un país desigual, tanto en términos de la distribución de la riqueza como en relación con el acceso de los nicaragüenses al sistema político y, con ello, a la toma decisiones que emanan del Estado. Esta desigualdad histórica ha generado una pequeña élite que ha controlado la mayor parte de la riqueza del país y el poder político asociado al aparato estatal. El origen de esta minoría todopoderosa se remonta a la estratificación social heredada del periodo colonial. En otras palabras, la perenne desigualdad económica y política que ha aquejado a Nicaragua durante toda su historia de república independiente es producto de la continuidad de la estructura social jerárquica instaurada por los españoles durante casi 300 años de dominación colonial, la cual permaneció vigente con algunas alteraciones, más formales que de fondo, durante el siglo XIX e inicios del siglo XX.

La estratificación social de Centroamérica durante el período colonial se basaba en la idea de que la sociedad estaba constituida de manera jerárquica. Se miraba como algo imposible la existencia de un orden social si no se recurría a la diferenciación entre estratos sociales inferiores y superiores (Luhmann, 1997, p. 679). Este ordenamiento jerárquico era la distinción primaria con la que se realiza la diferencia social, la cual servía para regular la inclusión y exclusión de una persona en la política, las instituciones religiosas y la distribución de la riqueza. En concreto, esto significa que la pertenencia a un estrato social determinaba cuánto poder político o riqueza podía llegar a tener una persona.

Esta estructuración jerárquica, que se puede representar como una pirámide, estaba conformado por cinco estratos: los indios, los mulatos/zambos, los mestizos, los criollos (españoles americanos) y los españoles peninsulares. El orden de estos rangos y el pertenecer a uno de ellos dependía de la cercanía cultural y étnica a lo español (Lockhart, 1984, pp. 285-288). Al respecto, Severo Martínez Peláez señaló muy bien que "el origen hispano daba superioridad -así se decía- más superioridad [...] cuanto más puro y cercano fuera ese origen" $(1998$, p. 88), de ahí que en la cúspide de esta pirámide social se encontraban los nacidos en España. Por debajo, se ubica a los criollos, es decir, las personas de padres españoles nacidos en América, seguidos por los mestizos, los mulatos/zambos y los indios en la base inferior de la jerarquía (ver Figura 1).

\author{
Españoles \\ Criollos \\ Mestizos \\ Mulatos/Zambos \\ Indígenas
}

Figura 1. Los estratos sociales en el Reino de Guatemala antes de la independencia de la Corona Española. ${ }^{1}$ 
Los españoles y los criollos constituían una pequeña minoría. Para el año 1778, la población de Centroamérica fue contabilizada en un total de 820.145 personas. La mitad de éstas eran indígenas y habitaban, en su gran mayoría, en las provincias de Chiapas y Guatemala. En ambas regiones, el 80 por ciento de la población pertenecía a este grupo étnico. En los casos de El Salvador y Nicaragua, el 50\% eran indígenas. Después de los indígenas, el segundo grupo poblacional más grande eran los mestizos o ladinos ${ }^{2}$, es decir, las personas cuyos padres pertenecían a diferentes grupos étnicos. El país con la mayor cantidad de mestizos, ladinos y negros libres era Costa Rica, con el 85 por ciento de la población catalogada como ladinos. Los españoles eran sólo una pequeña proporción del total de la población. En ninguna de las provincias había más de un 7 por ciento; en Chiapas y El Salvador, los españoles representan menos del 5 por ciento (Carolyn y Pérez Brignoli, 2003, p. 86). No obstante, los criollos y los españoles eran el estrato más rico (Solórzano, 1990 p. 42), pues su riqueza se derivaba principalmente de la explotación de la población indígena. Tres elementos componían este sistema de explotación: el tributo, el trabajo forzoso y el intercambio comercial obligatorio con los españoles (Solórzano, 1990, p. 39). El único beneficio que obtenían los indígenas de este sistema era que se les otorgaba cierto grado de libertad para gobernarse (Dore, 2006, p. 34).

La concentración de la riqueza, como resultado de este sistema de explotación, y su aceptación como un orden natural muestran que la estratificación era la estructura social de América Central. Por eso, la ocurrencia de esta distribución desigual de los recursos no es sorprendente, como tampoco lo es la sanción y la promoción, por parte del régimen colonial, de la explotación de todos aquellos que no eran considerados españoles o criollos. Esto fue sustancial a la estratificación social, cuya continuidad y reproducción como estructura social requiere de la existencia de lo anteriormente descrito. Su consecuencia es que genera un estrato superior, en términos numéricos pequeños, capaz de imponer su posición privilegiada al resto (Luhmann, 1997, p. 680). El caso del colonialismo español en Centroamérica constituye un buen ejemplo. Aquí, una minoría étnica, integrada por aquellos considerados como españoles, gobernaron sobre el resto de la población, sin enfrentarse a ninguna oposición o resistencia que pusiera en peligro su dominación (Romero Vargas, 1991, p. 71). El principal criterio para justificar esta estratificación social y su sistema de explotación era la cercanía a la cultura española y al fenotipo europeo. Esta norma, en la que se basaba la jerarquía social, se justificaba con las ideas de la superioridad moral atribuidas a los españoles. Todos los demás eran vistos como moral y culturalmente inferiores; desdeñosamente, a los no europeos se les consideraba salvajes.

La posición de un individuo en la jerarquía social era fija y regulaba su acceso a la tierra y a ser nominado a un puesto político o religioso. Especialmente difícil era la situación de aquellos que no eran españoles o indígenas, como los mestizos. $\mathrm{Su}$ aparición era algo que no estaba prevista por las normas jurídicas del régimen colonial. En el inicio de la dominación colonial, en términos legales, la Corona española no consideró la posibilidad de que emergiera un sector mixto de la población. 
Cuando éste apareció y su número aumentó, sus miembros fueron vistos como una amenaza al orden social establecido. A menudo, se hacía referencia a ellos con palabras peyorativas como "malhechores, vagabundos e ignorantes" (Díaz Arias \& Soto Quirós, 2007, p. 29). Por lo general, tenían que ganarse la vida convirtiéndose en sirvientes de los españoles y los criollos o dedicarse a trabajos de tipo artesanal, como ser herrero o talabartero. Otros se dedicaban a la agricultura y entregaban parte de su cosecha al dueño de la propiedad. En resumen, eran personas sin tierra, obligados a viajar de un lugar a otro para desempeñar trabajos de poca remuneración (Kinloch Tijerino, 1990, p. 65).

Una forma de mantener en pie este acceso desigual y restringido era por medio de la práctica de la endogamia entre quienes pertenecen al estrato superior (Luhmann, 1997, p. 680), lo cual fue practicado por criollos y españoles, quienes estaban estrechamente relacionadas entre sí por lazos familiares (Solórzano, 1990, p. 42). ${ }^{3}$ Por lo general, los individuos que pertenecían al mismo grupo étnico se casaban entre sí; estos matrimonios también permitían ampliar el poder político y económico de las respectivas familias. La práctica común era que las hijas de las familias españolas ya establecidas se casaran con los recién llegados de España, quienes en su mayoría eran hombres (Romero Vargas, 1991, p. 74). Así, el matrimonio posibilitaba ascender de un estrato a otro. Sin embargo, su principal función era garantizar el absoluto control de los españoles del poder político y económico, lo cual a su vez generaba la exclusión del resto de la población (Romero Vargas, 1991, p. 72).

La situación de exclusión y estigmatización de la población indígena era otra expresión de la estratificación social. En la época de la independencia de Centro América, un indio no podía formar parte de la jerarquía de la Iglesia católica. Tampoco se le permitía ser militar o miembro de la burocracia estatal, pues los indígenas, españoles, criollos, mestizos y mulatos no eran vistos como iguales. De los indios se tenía una imagen negativa; para referirse a ellos, se usaban términos desdeñosos. "El ser indio", era sinónimo de "ignorante”, "inculto", "salvaje”, "haragán” y "malicioso" (Baldovinos citado en Ayala Benítez, 2007, p. 24). Desde este punto de vista, ellos eran naturalmente inferiores $y$, por ende, la posición privilegiada de los españoles en la jerarquía social de la Centroamérica colonial era legítima.

En este contexto, existía poco espacio para ascender de un estrato a otro. Ser parte de la minoría dominante era únicamente posible si se pertenecía a una de las familias situadas en la cúspide de la pirámide social. El ingreso a una de estas familias se lograba sólo a través del matrimonio. Al mismo tiempo, estas familias del estrato superior se casaban exclusivamente entre ellas o con nuevos ricos (Lockhart, 1984, p. 267). De este modo, reproducían la exclusión de los estratos inferiores al restringir el ascenso social y reafirmaban los criterios legitimadores de la estratificación. A su vez, la Corona española deseaba impedir los matrimonios entre los estratos y, con ello, los movimientos ascendentes en la jerarquía social. Para lograr este acometido, se prohibió a los miembros de las fuerzas armadas casarse con quienes no fuesen consideradas españolas (Lavrin, 1984, p. 325). 
En resumidas cuentas, Centroamérica, en el momento de la independencia y después, era lo que Niklas Luhmann definiría como un sistema social cuya forma interna de diferenciación era la estratificación social (Luhmann, 1997, p. 685).

\section{LA ESTRATIFICACIÓN SOCIAL DESPUÉS DE LA INDEPENDENCIA}

Con la Independencia de Centroamérica, no se superó la estratificación social. Si se tiene en cuenta que esta ruptura histórica fue el resultado de la influencia de factores externos, no es extraño que la estratificación social haya continuado. La misma Declaración de Independencia muestra claramente cómo persistía el deseo de impedir la ocurrencia de cualquier cambio que llegara a modificar el orden social establecido por el Imperio Español. El primer artículo de esta declaración constata que el propósito de separarse de España era "prevenir las consecuencias que serían temibles en el caso de que la proclamase de hecho el mismo pueblo" (Esgueva Gómez, 2000, p. 110). Así, la independencia fue una medida necesaria para salvaguardar el orden social existente y evitar las posibles consecuencias negativas que podría tener para una minoría gobernante que ésta fuese realizada por los estratos bajos, a los que la declaración de independencia llama "el pueblo". La separación de España llevada a cabo por "el pueblo" podría haber conducido a la pérdida de la posición privilegiada de los españoles y criollos e inclusive al total aniquilamiento del orden social colonial, como había sucedido con la independencia de Haití, donde se dio una transformación radical del país, cuyo resultado fue la liberación del estrato social más bajo, como eran los esclavos africanos, y una distribución menos concentrada de la posesión de la tierra (Knight, 2000, pp. 104-105). Si se quiere ver la independencia de Centroamérica como una emancipación, se ha de recalcar que ésta fue sólo para unos cuantos. La nimiedad de los cambios que trajo consigo es resaltada por la inmovilidad de las autoridades coloniales en sus cargos hasta el primero de marzo del 1822, fecha en que los representantes de todas las provincias se reunieron en la Ciudad de Guatemala para confirmar la Declaración de Independencia como nueva forma de gobierno y redactar una constitución (Esgueva Gómez, 2000, p. 111).

El único cambio político que trajo la independencia fue el cese de la exclusión política de los criollos y, en menor medida, de los mestizos. José Cecilio del Valle, quien fue un importante intelectual y político durante y después del proceso de independencia, claramente declaró la aspiración de los criollos a ser considerados como iguales a los españoles peninsulares. En un artículo de noviembre de 1821, escribió que el "americano" también era hombre y que la naturaleza le había otorgado a este hombre americano, los mismos derechos que se habían defendido hace poco en Europa, ya que ambos eran "individuos de una misma especie", Es decir, eran seres humanos "iguales y libres por naturaleza". A esto se sumaba la consecuencia de que, si los europeos no aceptaban ser gobernados desde América, los americanos tenían el derecho de negarse a someterse al dominio europeo. Dice del Valle: 
"si unos y otros han creído imposible ser bien regidos por un Gobierno distante de sus hogares, los Americanos tenemos iguales derechos para dar el mismo grito y publicar la misma opinión" (del Valle, 1969, pp. 181-182). En estas palabras se ve cómo la Declaración de Independencia de España sirvió a los criollos para declararse, en términos políticos y sociales, iguales a los europeos, o por lo menos, tal como ellos lo entendían, éste era el acto que establecía esa igualdad. En este sentido, la independencia de Centroamérica fue el proceso político por medio del cual los criollos ricos obtuvieron el poder que la Corona Española les había negado. No se trató de una transformación profunda o un cambio radical del orden social implementado por el régimen colonial. Más bien, se puede entender como una serie de acontecimientos que llevaron a los criollos a convertirse en el rango superior de la jerarquía social de Centroamérica, y, por ello, la independencia tampoco impulsó la modernización política y social de la región.

En el caso de la población indígena, nada mejoró. Comparados al resto de la población, continuaron siendo vistos como inferiores. Todos los otros estratos fueron catalogados como más "europeos" y "civilizados". La inferioridad de los indios no se sostuvo con base a una idea de superioridad derivada de diferencias biológicas o morfológicos a como se hizo en el siglo XIX y XX. Simplemente, se percibía su cultura como inferior. En opinión del estrato superior, integrado en su mayoría por criollos, ellos mismo eran el sector más "civilizado" de la sociedad porque su cultura era parte de la ilustración europea. Los indios, por el contrario, necesitaban todavía ser "civilizados" para que fueran capaces de participar en política y se convirtieran en miembros de la "comunidad política" (Acuña Ortega, 2005, p. 267). De esta manera, se justificaba la exclusión de la población indígena de la política y se declaraba su inclusión como un proyecto para ser realizado en el futuro en dependencia de la pérdida de su cultura y la adopción de la europea.

Tal como había sido la norma antes de la independencia, los criollos continuaron viendo a Centroamérica en términos jerárquicos. Para ellos, América Central se componía de tres grupos. En la parte superior, estaban los propios criollos, seguidos por los artesanos, que en su mayoría eran mestizos y mulatos. Durante el período colonial, estos últimos habían ocupado el estrato intermedio entre criollos e indígenas. Al igual que durante la colonia, en la parte inferior de la nueva jerarquía social se encontraban los indígenas (Acuña Ortega, 2005, pp. 263-266). Según Víctor Hugo Acuña, los criollos miraban a los artesanos de dos formas. Por un lado, los consideraban como ciudadanos legítimos e importantes educadores de la "plebe" y, por el otro, como "intermediarios" entre ellos y "el populacho". Sin embargo, los artesanos no eran sus iguales en términos morales y sociales. Sólo eran iguales al estrato dominante ante la ley, pero nada más (Acuña Ortega, 2005, p. 265). Para el estrato superior, es decir para los criollos, los artesanos eran gente moralmente inferior debido a su ignorancia y falta de buenos hábitos. En el periódico El Editor Constitucional, publicado en la Ciudad de Guatemala por un grupo de intelectuales a favor de la independencia y dirigido por el médico Pedro Molina (Fry, 2008, pp. 654-655), este estrato era descrito despectivamente. 
Se consideraba que los artesanos vivían "en la oscuridad" y "sumergidos" en un estado de ignorancia "vergonzosa". Como consecuencia, los artesanos merecían ser vistos con desdén y eran dignos de rechazo. Según el autor del texto, el artesano era "inmoral", "insubordinado" y padecía de "los vicios más vergonzosos" debido a dos razones, su desobediencia a las buenas costumbres y su falta de educación y cultura (Molina, 1954, p. 180).

Este juicio moralizante del estrato superior acerca de los artesanos es también una manifestación de la estratificación social, la cual se legitima con la presunción de que los estratos son diferentes en cuanto a su naturaleza y su carácter moral (Luhmann, 1997, p. 682). En palabras más simples, se puede decir que la jerarquía social se legitimaba de acuerdo con el siguiente razonamiento: los estratos inferiores no son iguales al superior porque no se comportan de la misma manera, y esta discrepancia es producto de su inferioridad natural y moral. A su vez, el comportamiento del estrato situado en la cúspide de la jerarquía es superior debido a su propia condición natural. Por ello, se afirma que la igualdad es solamente posible ante la ley, pero "que nunca podrán ser iguales en la fuerza física, en los talentos y en las ventajas que uno y otro proporciona" (Molina, 1969, p. 363).

Esta perspectiva de los criollos respecto de la condición natural de inferiores del resto de la población comprueba cómo fundieron "su propia identidad con una concepción jerárquica de toda la sociedad" y cómo al hacerlo delimitaron "los lugares de los otros"s (Luhmann, 1977, p. 34). De ahí que, para los criollos, Centroamérica estaba integrada por tres grupos desiguales: ellos mismos, los artesanos y los indios. Esta concepción revela cómo el orden social jerárquico y la estratificación social permanecieron inalterados después de la independencia de España; además, permite concluir que no hubo una verdadera ruptura con la estructura social impuesta por el régimen colonial.

\section{LA ESTRATIFICACIÓN SOCIAL EN EL SIGLO XIX}

Durante el resto del siglo XIX, se mantuvo viva la estratificación social y la exclusión que la acompaña. Así, por ejemplo, durante el periodo de la república conservadora en Nicaragua (1858 a 1893) instaurada después del traumático episodio que significó la llegada de William Walker, existía la perspectiva de que no todos los nicaragüenses eran igualmente aptos para participar en política. Un artículo sobre la educación, publicado en el Mentor Nicaragüense en 1841, muestra como no a todas las personas se les atribuían los mismos derechos políticos y que la participación en la política era concebida en términos distintos. El artículo argumenta que la educación dirigida a un finquero no tenía que prepararlo para convertirlo en un juez o un político. Tampoco debía la educación de un artesano prepararlo para gobernar o para tener alguna influencia en el gobierno. Su educación sólo le debía enseñar a amar a su país y a ser virtuoso. Se argumentaba que todos los nicaragüenses debían tener acceso a la educación pública, pero no todos debían recibir la misma educación (Mentor Nicaragüense, 1841). 
De esta manera, el carácter estratificado de la sociedad nicaragüense del siglo XIX debía reflejarse en la educación que recibía cada persona. Por ello, sólo a unos pocos hombres se les otorgaba el derecho a ser educados para dedicarse a la política. El resto estaba simplemente excluido, pues se consideraba que su condición natural no los hacía idóneos para inmiscuirse en el oficio de gobernar.

También la rebelión de los matagalpas de 1881 nos refleja la continuidad de la estratificación social. La rebelión violenta fue la única respuesta que pudieron dar los indígenas ante la penetración autoritaria e inconsulta del Estado en su territorio y vida. La tajante exclusión a la que estaban sometidos, nos les dió otra opción para enfrentar y oponerse a las políticas del Estado que la revuelta violenta. La causa de esta rebelión fue su descontento respecto del tratamiento que recibían por parte del Estado nicaragüense, dominado por los criollos y los mestizos. Estos últimos consideraban a los indios inferiores y los sometían al trabajo forzoso y al reclutamiento militar obligatorio, entre otras medidas. Escuetamente, se puede decir que los indígenas luchaban, al mismo tiempo, en contra de la intervención del Estado ladino en su vida diaria y para resistir la opresión que sufrían (Gould, 1998, pp. 33-43).

La rebelión duró diez días, en los cuales los indígenas atacaron y sitiaron la actual ciudad de Matagalpa (Miranda Casij, 1972, pp. 75-82) que, en aquellos años, era un pequeño poblado de 3000 habitantes (Gould, 1998, p. 27). La rebelión fue su respuesta a tres medidas aplicadas recientemente por el gobierno central: expulsar a los jesuitas de Nicaragua, prohibir la producción de chicha (bebida hecha a base de maíz fermentado) e implementar el reclutamiento forzoso para asegurarse la mano de obra indígena en la construcción de la línea telegráfica entre Matagalpa y la capital (Miranda Casij, 1972, pp. 75-78). Esta rebelión era la única forma de resistencia que tenían los indígenas para defenderse del brutal sistema de explotación al que se encontraban sometidos desde los tiempos de la colonia española y que con la independencia de Centroamérica poco había cambiado. En el presente caso, el telégrafo se había convertido en el símbolo y la materialización de la explotación que, desde los tiempos del imperio español, sufrían los indígenas. Su construcción se había realizado con el trabajo "voluntario" de los indígenas. Sin embargo, este trabajo no había sido del todo voluntario. Por ley se ordenaba al ejército que persiguiera y forzara a trabajar a todo aquel que se negara (Miranda Casij, 1972, pp. 75-78) y que fuera catalogado como vago, siendo los indígenas las principales víctimas de esta norma jurídica.

En esencia, este trabajo forzoso era una nueva versión del sistema de encomienda con el cual, durante la colonia, los españoles habían obligado a la población indígena a trabajar sin remuneración. Según Silvio A. Zavala, la encomienda se basaba en "el principio de la compulsión estatal para el trabajo del indígena, en sustitución del régimen contractual del libre asalariado; el trabajo quedaba bajo la vigilancia oficial, y la retribución del jornalero era tasada por el Estado, no por acuerdo libre entre patronos y trabajadores" (Zavala, 1935, p. 4). En efecto, este era un sistema tributario en el cual el pago de los indígenas a los encomenderos se daba en forma de tributos y trabajo. 
Los encomenderos eran los españoles encargados por la corona española de cuidar a los indios (Knight, 2008, p. 126). De manera similar, en 1881 los indígenas matagalpas estaban obligados a trabajar para el Estado nicaragüense y para aquellos que lo controlaban, sin recibir salario alguno. De esta manera, sesenta años después de la independencia de España, la población indígena en Nicaragua continuaba sometida a un sistema de explotación de su fuerza laboral. Dicho sistema de trabajo forzado se mantuvo vigente de manera informal hasta los años 30 del siglo XX en la producción cafetalera (Gould, 1993, p. 417).

Sin embargo, la vigencia de la estratificación social no solo se manifestó en la permanencia del trabajo forzado durante todo el siglo XIX e inicios del XX, sino también en el marcado carácter excluyente del acceso a la educación en general y especialmente a la educación superior. Ello lo evidencia el porcentaje de alumnos que asistía a la escuela secundaria. Para el año 1895 , se estimaba que de 19.320 alumnos que asistieron a la escuela primaria, sólo 1.441 pasó a la escuela secundaria. En porcentaje, esto era el 7,5 por ciento. La diferencia demuestra que exclusivamente una pequeña minoría accedía a la educación secundaria y universitaria en la Nicaragua del siglo XIX. Si se compara el número de estos privilegiados con el resto de la población nicaragüense, estimada en 337.000 personas en 1870, se constata que aproximadamente el 6 por ciento de la población poseía algún tipo de educación. Estas cifras dan una idea de cuán limitado era el acceso a la educación general y cómo, por esa razón, sólo una minoría era capaz de participar en el debate político de la época (Ayerdis, 2005, pp. 91-92).

\section{LAS REPERCUSIONES DE LA ESTRATIFICACIÓN SOCIAL EN EL SISTEMA POLÍTICO NICARAGÜENSE}

Las repercusiones de la estratificación social en el sistema político son múltiples. La primera que se puede señalar es la monopolización de la actividad política por unas cuantas familias que se da durante gran parte del siglo XIX. Probablemente la familia más famosa que dominó la política nicaragüense hasta las primeras décadas del siglo XX y que retornó a la presidencia de la república después de la Revolución Popular Sandinista fue la familia Chamorro. A lo largo de la historia de esta familia, se pueden contar por lo menos a 4 presidentes y si se incluye a doña Violeta Barrios de Chamorro, este número asciende a 5 . El primer presidente perteneciente a esta familia fue Fruto Chamorro, quien gobernó Nicaragua de 1853 a 1855. A él le sigue Pedro Joaquín Chamorro Alfaro quien estuvo en la silla presidencial en el periodo que va 1875 a 1879 . En el siglo XX, durante el periodo de la ocupación militar e intervención financiera de los Estados Unidos, llegaron a la presidencia dos Chamorros, primero Emiliano Chamorro en 1917 hasta 1920 y después su tío Diego Manuel Chamorro en 1921. El primero incluso regresó brevemente al gobierno en 1925 gracias a un golpe de estado que pasó a la historia bajo el nombre de El Lomazo. 
Así, esta familia y otras familias, los Sacasa y los Cuadra, fueron los que dominaron la política nicaragüense durante el siglo XIX e inicios del XX.

En la literatura que ha analizado la política y la historia de Nicaragua y Centroamérica, a estas familias se les ha denominado con el término Oligarquía (Núñez, 2006; Torres-Rivas 2011). Este concepto, aunque ha servido para señalar la dominación política y económica de una pequeña minoría, no se ha ocupado en analizar las condiciones sociales producidas por el entorno social que han permitido su existencia y continuidad. Pues pasa por alto como la estructura social, es decir la estratificación, presenta la condición necesaria para que estas familias continuaraeún siendo la minoría dominante, ya que genera un acceso diferenciado a la política, la economía, la educación, entre otros sistemas sociales. Este acceso privilegiado para una minoría y la exclusión para la mayoría era regulado por dos factores: la pertenencia a una de las familias que componían el estrato alto y sus vínculos sociales, ya que los integrantes del estrato superior se relacionaban principalmente con quienes pertenecían al mismo estrato. Quien no fuera de una de estas familias y, por ende, del mismo rango social, no tenía derecho a controlar la posición de poder más importante en el país, como por ejemplo la presidencia, ya que eran visto como carente de las cualidades necesarias para detentar tanto poder.

La pretensión de exclusión y de monopolizar el control del Estado de estas familias se basaba en que se miraban a sí mismas como "la más alta sociedad política y financiera [...] de toda Nicaragua" (Cardenal Tellería, 2000, p. 486), como "la sociedad ilustrada" (Cuadra Pasos, 1976, p. 419), y sus miembros eran "de noble familia" (Tijerino, 1964, p. 29), de "ilustre sangre" (Tijerino, 1964, p. 30) y poseían "ascendencia ilustre" (Montalván, s.f., p. 71). Calificativos que reflejan claramente cómo en Nicaragua predominaba una concepción jerárquica del orden social. Así se fijaba una marcada diferencia entre las familias que componían la más alta sociedad y el resto de los nicaragüenses, quienes eran vistos como "la masa rústica" (Cuadra Pasos, 1976, p. 419), lo cual a la vez demuestra que existía una forma de diferenciación social en la que una minoría se consideraba a sí misma como superior al resto de los habitantes del país al atribuirse un estatus de superioridad moral y natural. En consecuencia, se generó una polarización política en términos excluyentes que resultaba antidemocrática, pues la dominación política oligárquica y su control monopólico del Estado dejaba por fuera a la gran mayoría de la población. La respuesta de los excluidos ante esta situación fue la violencia, pues ellos no concebían otra forma de lograr la alternancia en el poder y de hacer valer sus intereses políticos.

Así, este conflicto se materializa repetidamente en una confrontación bélica. Un ejemplo esfue la guerra civil de 1912, la cual que dió pieprodujoa la primera ocupación militar de Nicaragua por parte de los Estados Unidos y se dió como fue el resultado del enfrentamiento entre quienes deseaban "la restauración del viejo sistema de gobierno patriarcal, contemporizador, con los Poderes Públicos flotando sobre una honorable y culta oligarquía" (Cuadra Pasos, 1976, p. 601) y aquellos que ambicionaban ponerle fin a esta dominación oligárquica. 
Estos últimos prometían que cuando alcanzaran la victoria, "el pobre humillado, explotado, escarnecido por una insolente oligarquía, tendr[ía] pan para sus bocas hambrientas y lienzo para cubrir sus ateridos cuerpos desnudos" (Benjamín Zeledón, 1977, p. XX). A como podemos ver en esas palabras, los antioligarcas se consideraban a sí mismo los salvadores del pueblo, el cual a la vez era equiparado con los estratos más bajos y excluidos de Nicaragua. También tenían la idea de que los estratos bajos y excluidos, por aquellos que se consideraban ser las nobles familias de Nicaragua, eran el pueblo nicaragüense y en consecuencia el adversario oligárquico no era parte del pueblo. A su vez, ellos no solo defendían al pueblo, sino que también eran sus representantes, ya que provenía de estos estratos bajos. Se puede ver claramente en la imagen que proyectaba su principal líder, el general conservador Luis Mena, quien era considerado por sus seguidores un "hijo del pueblo" y un representante de los "inditos, zambos, mulatos o mestizos" (Gobat, 2005, p. 85) (Kinloch Tijerino, 2004, p. 130).

Una imagen similar, pero en sentido negativo, le atribuían los tradicionales integrantes del estrato superior nicaragüense tanto a Mena como a su aliado liberal Benjamín Zeledón. Para ellos, ambos representaban lo que en aquellos años consideraban era una nobleza corrupta en dos sentidos. Primero, porque su ascenso social era visto como el resultado de la corrupción del régimen de Zelaya (1896-1909) (Gobat, 2005, p. 92), durante cuyo régimen las viejas familias habían perdido "su fortuna por las fuertes multas y contribuciones forzosas" (Cuadra Pasos, 1976, p. 573) que les habían sido impuestas. En segundo lugar, esta nueva nobleza estaba integrada por "mulatos, mestizos y cuarterones" (Gobat, 2005, p. 92), es decir, por individuos de origen racial inferior frente a quienes proclamaban representar "la inteligencia, riqueza y la sangre española más pura de Nicaragua" (The American Minister to the Secretary of State, 1912, p. 1059) ${ }^{6}$ Para ellos, estos advenedizos no eran "ilustres" y tampoco se distinguían del pueblo común; igualmente, sus aspiraciones de nobleza se basaban únicamente en el dinero que poseían (Gobat, 2005, p. 92). Por estas razones, no podían ser parte del estrato gobernante. El meollo del conflicto consistía en que "las viejas familias", que se entendían a sí mismas como los descendientes de los criollos españoles, se sentían amenazadas por "una burguesía de nuevos ricos" (Cuadra Pasos, 1976, p. 573) que carecía de legitimidad en términos morales y de origen. De ahí que, para este patriciado criollo, los nuevos ricos no tenían la superioridad moral y natural derivada de su linaje racial y social. Por lo tanto, carecían de las cualidades requerida para poder pertenecer al estrato superior y tener el derecho a gobernar el país.

En este sentido, se puede decir que esta confrontación era vista como el enfrentamiento entre el "pueblo" y la "oligarquía", en el cual el concepto de pueblo hacía referencia a los estratos excluidos y/o marginados del sistema político y económico. Al mismo tiempo, el concepto de oligarquía era usado para señalar al estrado alto y a su dominio económico y político excluyente. Así, lo que para las viejas familias patricias era su santo derecho, los partidarios de Mena y Zeledón lo definen como una injusticia social e inmoralidad. Desde esta perspectiva, se proclamaba la ilegitimidad del dominio político de estas familias y la necesidad de acabar con su gobierno. 
El problema de esta noción del conflicto político como la lucha entre "el pueblo" y la "oligarquía" era que no superaba la diferenciación social basada en la distinción de estratos superiores e inferiores. En otras palabras, se mantiene la diferenciación entre estrato superior e inferior por medio de la contraposición de "pueblo" y "oligarquía".

Por ello, se permanecióomantenía intacto el carácter excluyente del sistema político, ya que se recurría al término oligarquía para justificar la propia lucha y deslegitimar el poder político del oponente. Así, el bando que se definía como antioligárquico podía autodenominarse representante del pueblo y catalogar a su oponente como el enemigo de éste. De esta manera, le negaba al otro su derecho a tener influencia política y a ser parte del sistema político, a como el otro a su vez se las estaba negado. Esto significa que se proclamaba la exclusión inversa de la que se eras víctima para legitimar el propio dominio excluyente sobre la toma de decisiones políticas que incumben y afectan a todos los habitantes del país. Simultáneamente, no se lograba superar la dinámica de exclusión con la que estaba operando el sistema político nicaragüense desde la independencia y que ha hecho de las guerras civiles y las rebeliones armadas un fenóomenohecho recurrente durante el siglo XIX y XX. En el fondo, se da la reproducción en el sistema político de la exclusión generada por la jerarquización social que funciona con base en la diferenciación vertical de "los de arriba" y "los de abajo". Sólo que en el sistema político la distinción se reconfigura en términos de "oligarquía" versus "pueblo", así como "buenos" versus "malos", en la cual cada bando se ve a sí mismo como los buenos y los únicos dotados de la legitimidad de gobernar el país. En el caso de Mena y Zeledón, ellos se considerabason los buenos por dos razones: 1) porque pretendíaen redimir al pueblo de la explotación de la oligarquía a la que ven como "los malos" y 2) por que representarn y lucharn por el pueblo, es decir, por "los de abajo", mientras que sus oponentes representaban a "los de arriba" (la oligarquía) que siempre has excluido y explotado a los de abajo, es decir, al pueblo. El resultado es una dinámica de polarización política que promueve una constante enemistad y un conflicto político antitético que se convierte en el continuo intento de aquellos que se consideran los representantes del "pueblo" por excluir a los enemigos del "pueblo" del sistema político.

La gran paradoja de cómo el bando antioligarca ve el conflicto político y social en el cual se encuentra inmersos es la que genera su incapacidad de superarlo, pues sin darse cuenta reproduce la exclusión política y social imperante en su entorno cuya abolición desean alcanzar. El problema está en que para superar esta exclusión es necesario deshacerse de la desigualdad y de las ideas que la sostiene, lo cual no es posible si se ve la propia lucha en los términos antes referidos.

Dicho con otras palabras, la diferenciación estratificada de la sociedad se refleja por medio de esta dinámica de exclusión mutua y violencia en el sistema político, sin nunca lograr superarla. En consecuencia, no se logra hacer lo que se propone, que es superar la antítesis pueblo/oligarquía y pobres/ricos, ya que se recurre a la diferenciación jerárquica que subyace en la contraposición de estos conceptos para legitimar la propia lucha y las aspiraciones políticas que la impulsan. 
Para lograr superar esto, se tiene que apuntar a no entender a los ricos/oligarcas como diferentes a los pobres/pueblo. Se requiere verlos como iguales y darles el mismo tratado de facto en las mismas circunstancias, independientemente del origen social, familiar, cultural, étnico o de género.

\section{LA POLÍTICA NICARAGÜENSE COMO JERARQUÍA: CAUDILLISMO Y PERSONALISMO}

Otra consecuencia en el sistema político de la desigualdad que impera gracias a la estratificación y que refuerza esta dinámica violenta de mutua exclusión es la estructura jerárquica del sistema político, producto de la repetición en su interior de la estratificación de toda la sociedad nicaragüense. El caudillismo y el clientelismo son una clara manifestación de esto, ya que generan un acceso desigual y estratificado. Esto se debe a que el caudillismo, esn un sistema jerárquico de toma de decisiones, se expresa en en el que la posición de alguien en esta jerarquía de dependencia de una persona con su cercanía al caudillo. Por ello, la capacidad de una persona de influenciar la toma de decisiones políticas está igualmente determinada por esta cercanía y por de la voluntad arbitraria del caudillo.

Sin embargo, el caudillismo no es un sistema de sumisión pasiva al líder, en el que éste puede disponer irrestrictamente de sus seguidores e imponer ilimitadamente su voluntad. Más bien, se trata de un sistema de intercambio de favores y de continuas negociaciones de lealtades que generan el apoyo político adel caudillo. En esto, los lazos personales son vitales, al producir la confianza necesaria para mantener la reproducción del intercambio. Además, estos lazos personales son lo único que aseguran alguna influencia sobre el proceso de toma de decisiones, ya que no existen otros mecanismos para condicionar a la dirigencia política, como lo permitiría un sistema electoral competitivo basado en la igualdad política de los ciudadanos que les permite -potencialmente- tener el mismo igual acceso a la toma de decisiones políticas.

Esta importancia de los lazos personales ha sido otra característica central de la política nicaragüense durante el siglo XIX e inicios del XX y se ha manifestado en el excesivo personalismo del sistema político nicaragüense. Este personalismo ha fomentado el carácter jerárquico del que ha adolecido el sistema político y que ha ignorado las demandas y los intereses de la mayoría de la población, pues para legitimar y garantizar el poder político del líder/caudillo son más relevantes las relaciones personales con sus allegados y demás seguidores que los deseos, aspiraciones y necesidades del resto de la población. En esta situación, la satisfacción de los intereses de la mayoría de la población era irrelevante para llegar al poder y mantenerlo, pues su apoyo voluntario no representaba un requisito imprescindible. El reclutamiento forzoso con base al cual se garantizaba el número de soldados requeridos en las continuas contiendas bélicas nos demuestra claramente la irrelevancia política de la voluntad de esta gran cantidad de nicaragüense pertenecientes a los estratos bajos. 
A esto se le debe agregar que durante todo este periodo y hasta la década de 1970, el principal mecanismo con el que se lograba el cambio de gobierno o mantenerse en el poder era por medio de las armas, lo cual podría tomar la forma de una guerra civil, una rebelión armada y/o la represión política como la que se está ejecutando en la actualidad. Uno de tantos episodios de la represión que se han dado en la historia de Nicaragua, lo vivió el liberal Juan Carlos Serrano, quien, una vez que los rebeldes libero-conservadores derrocaron al presidente José Santos Zelaya en 1909, fue sometido al "trato más salvaje é inhumano; haciéndose[le] dormir en frío y asqueroso suelo, sin camas ni ropa, y frente á los bastos retretes" (Carlos Serrano, 1912, p. 2). Esta narración de una vivencia de tortura y humillación al oponente político es una de muchas que se han repetido en repetidas muchas ocasiones en el devenir histórico de la política nicaragüense.

Otro efecto importante que ha tenido el personalismo fuees que conveirtiró el conflicto político en una lucha entre amigos y enemigos. Al igual que sucede en la codificación del enfrentamiento político en términos de oligarquía/pueblo, se trata de un enfrentamiento entre un bando bueno y otro malo. Los amigos eran el lado positivo y legítimo (los buenos) y los enemigos, el lado negativo e ilegítimo (los malos) del enfrentamiento. Simultáneamente, los amigos son aquéllos que pertenecían al propio bando o grupo político, y los enemigos, al contrario. La importancia que tienen los lazos personales y la pertenencia al grupo de amigos se puede ver en los apelativos que se usan los bandos en pugna tanto para referirse a si mismo como a su rival. Así, por ejemplo, quienes apoyaban a inicios del siglo XX al presidente Adolfo Díaz, se autoproclamaban como "Amigos del Gobierno" (Tijerino, 1964, p. 17) o "los Verdaderos Amigos del Gobierno" (Cuadra Pasos, 1976, p. 453). Por su lado, los seguidores del caudillo Emiliano Chamorro, colega del partido conservador de Díaz y rival político, se llamaban a sí mismos "chamorristas" (Tijerino, 1964, p. 21).

Estos nombres demuestran claramente el carácter personalista de sus objetivos y del sistema político nicaragüense. La selección del nombre en sí misma era personalista, ya que pretendía demostrar y enfatizar la relación personal existente entre los integrantes y el líder político. En el caso de los "Amigos del Gobierno", esta relación era con el presidente Adolfo Díaz, cuyo objetivo era resaltar su cercanía al presidente y cómo esto les garantizaba el respaldo del poder político que éste ostentaba para salir victoriosos en las elecciones de 1916 (Tijerino, 1964, p. 20); mientras, los "chamorristas" expresaban, con su nombre, su lealtad personal al caudillo Emiliano Chamorro, a quien consideraban una persona virtuosa, políticamente hábil y con quien podían establecer una duradera relación personal (amistad). Un declarado "chamorrista" lo retrató en sus memorias como:

caballeroso en la amistad, generoso con el adversario, cordial con los humildes, exquisito con las damas, valiente en la acción como pocos lo fueron en la historia de Nicaragua. [...] amigos los tenía por millares y los reconocía siempre, en cualquier momento, no sólo a ellos sino también -y recordándolos por sus propios nombres- a sus padres, esposas, hijos y hermanos. (Borgen, 1979, p. 9) 
En esta imagen se aprecia como se idealizaba a la figura de Emiliano Chamorro, su liderazgo tenía algunas de las características de lo que Max Weber definió como la dominación carismática, en el sentido de que se le atribuían cualidades fuera de lo ordinario y de las cuales no estaba dotada cualquier otra persona (Weber, 1922, p. 140). Una de estas dotes extraordinarias era la gran memoria señalada en este retrato, que le permite cultivar las relaciones personales en las cuales se fundamentaba su liderazgo y poder político.

Como se puede ver, tanto la contraposición de pueblo y oligarquía, así como la confrontación en términos de amigos y enemigos con la que se estructuró el conflicto en Nicaragua conduce a una dinámica de interacción en done la pretensión de exclusión del adversario permanece en el perenne intento de eliminarlo por medio de la confrontación violenta en sus múltiples dimensiones. Simultáneamente, esta dinámica de exclusión mutua con la que funciona el conflicto político en Nicaragua produce una constante inestabilidad política, es decir, en la historia de Nicaragua, las crisis políticas violentas son un fenómeno recurrente y cuya reaparición nunca parece cesar. Para los bandos, el germen de esto es el oponente político y su incapacidad de actuar de manera racional. Por ello, una forma común a inicios del siglo XX de explicar este fenómeno era considerarlo como producto de las pasiones políticas de los individuos enfrentados. Así, por ejemplo, el General liberal José María Moncada describió la causa de las constantes guerras civiles en Nicaragua con las siguientes palabras: "si unos vencen, su primer deseo, su empeñoso ardor es vengarse del contrario, apoderarse de su hacienda, separarle de su hogar, y si fuese posible de esta vida. Los poderosos claman por el Poder, pero no piensan en la evolución, ni en elecciones, sino en otra guerra, en un golpe de fuerza y cuartel" (Moncada, 1932, p. 6).

Este retrato del conflicto político como resultado de pasiones irreflexivas (el deseo de venganza) de los bandos políticos, no fue algo exclusivo de su época. Desde los tiempos de la independencia de España, en Centroamérica se creía que estas "pasiones humanas" o "pasiones de facciones" eran las que alteraban el régimen constitucional que se pretendía establecer (Acuña Ortega, 2018,p. 254.) Aún autores nicaragüenses más contemporáneos han visto, por ejemplo, al golpe de estado de Emiliano Chamorro de la misma manera, al atribuirlo al "resentimiento del clan granadino" (Barahona, 1989, p. 38), es decir, a los sentimientos de los integrantes del Partido Conservador provenientes de Granada. El problema con esta apreciación es que reproduce continuamente el personalismo con el que opera el sistema político nicaragüense, pues fenómenos sociales y sucesos de la historia política son descritos y explicados como resultado de los sentimientos de individuos o grupos concretos.

De esta manera, se le atribuía a la persona lo que es producto de las operaciones del sistema político: la guerra como la operación que genera la alternancia del gobierno, por ejemplo. Por otro lado, no se lograr alcanzar la ansiada estabilidad política y la superación de la violencia como método para obtener el cambio de gobierno, pues implícitamente, igual que sucede con la noción de la oposición como la fuente de toda inestabilidad, su principal efecto es deslegitimar la existencia de 
diferencias políticas al reducirlas, de manera sumamente simplista, a un asunto de pasiones y, a la vez, ignorando cualquier otra posible causa. De ahí que se mantuviera la alternancia en el poder a través de la lucha armada como única forma posible de lograrlo. Al final, esta forma de analizar la política solo es una perspectiva que pretende manejar las divergencias de criterios, descalificándolas y reprimiéndolas. En realidad, lo que se hace es legitimar y justificar la persistencia de un sistema político en el que se rechaza la presencia de intereses múltiples y opuestos.

\section{CONCLUSIÓN}

Como se demostró anteriormente, la desigualdad generada por la estratificación social fue la forma de diferenciación social que estructuró a Nicaragua durante el siglo XIX e inicios del siglo XX. Esta se ha heredado del régimen colonial español y permaneció vigente durante todo el periodo aquí analizado. Su característica más importante es que el orden social imperante sólo se percibe como una jerarquía de segmentos o estratos desiguales, lo que tuvo profundas repercusiones sobre el sistema político nicaragüense. En primer lugar, condujo a que se diera un acceso restringido y desigual al sistema político. Por ejemplo, durante el periodo colonial, esto se manifestó en la exclusión de los criollos de los puestos políticos más importantes dentro de la burocracia colonial y la prohibición para los mestizos de poseer tierras. Después de la independencia, pese a que hubo importantes cambios, la estratificación social continuó. La modificación más relevante fue que los criollos pasaron a ocupar el lugar de los españoles peninsulares en la jerarquía. Así, estos tuvieron la posibilidad de desmontar la exclusión política y económica a la que habían sido sometidos durante la colonia. Sin embargo, para los indígenas que durante la colonia habían ocupado la posición más baja, no se dio ningún cambio significativo. La percepción del estrato superior (los criollos) respecto de ellos y de los artesanos (mestizos y mulatos), como moral y naturalmente inferiores, permaneció en pie y continuó legitimando la diferenciación social jerárquica. Todavía a inicios del siglo XX, se mantiene esta visión jerárquica del orden social nicaragüense. Así nos lo demuestra el lenguaje que usan los descendientes de las familias criollas que pasaron a dominar de manera excluyente y monopólica el quehacer político y el aparato del Estado Nicaragüense. Para legitimar este dominio excluyente, recurren a atribuirse a sí mismos una superioridad natural y moral y señalan al resto de la población como carentes de tales atributos.

En el sistema político, la estratificación social tuvo varias repercusiones. Primero, contribuyó a estructurar el conflicto político de tal manera que la búsqueda de su resolución por medio de la violencia fue una constante, lo cual se evidenció en la recurrente aparición de la violencia política durante el siglo XIX y XX. Esta estructuración del enfrentamiento político se puede describir como una dinámica de exclusión mutua de los bandos enfrentados, la cual refleja y es producida por la exclusión social predominante en todo el país. Dicha exclusión en el sistema político 
se traduce en la contraposición entre pueblo y oligarquía que se trata de resolver por medio de la guerra, como sucedió en la guerra civil de 1912. El problema de es que recurrir a la violencia para superar la exclusión a la que el estrato superior, también llamado por sus adversarios oligarquía, desea someter al resto de la población es que intensifica la dinámica de exclusión mutua y mantienen vigente la estratificación social al reproducir con una valoración inversa la misma concepción jerárquica.

Otro efecto importante de la estratificación social es que le imprime al sistema político nicaragüense un carácter marcadamente personalista que se expresa en el caudillismo y el clientelismo. Al mismo tiempo, Aambos fenómenos son la reproducción de la estructura jerárquica imperante en el entorno social en el sistema político, lo cual tienen como consecuencia el establecimiento de un acceso desigual y excluyente para la mayoría de la población al quehacer político. Esta preponderancia del caudillismo y el clientelismo se debe a que la estructura jerárquica llevó a que las lealtades y los vínculos políticos se basaran, en primera instancia, en las relaciones personales. Para quienes no pertenecen a la red clientelar personalista que se encuentra en el control del aparato estatal, el resultado es que no tienen la mínima capacidad de influir en la toma de decisiones políticas y, por ende, se ven obligados a recurrir a la violencia para hacer valer sus intereses ante el Estado Nicaragüense. Además, este personalismo convierte el enfrentamiento entre los diferentes bandos en una lucha entre amigos y enemigos, lo cual refuerza la dinámica de exclusión, la violencia política y la incapacidad de establecer un sistema político democrático en el que se acepta la divergencia de criterios y el derecho del oponente político a llegar a controlar el aparato estatal y dirigir el destino del país.

\section{NOTAS}

$1 \quad$ Figura 1: Elaboración propia.

2 El significado del término ladino tiene una historia compleja. Aquí el concepto es aplicado a los "Indians in Central America and elsewhere who have adopted Spanish forms of dress and behavior" (Levine, 1980, p. 74). Durante el siglo XIX en Nicaragua, ladino se convirtió en el vocablo usado para referirse a toda persona no indígena (Gould, 1998).

3 Al observar a las élites de Centroamérica y Nicaragua, se nota cómo esto acontece aún en la actualidad, lo cual permite considerar que todavía persiste cierto grado de estratificación social. Ver (Casáus Arzú, 2008, pp. 147-166).

4 En el original: "their own identity with a hierarchical conception for the whole society".

$5 \quad$ En el original: "the places for others".

6 En el original: "the intelligence, wealth and purest Spanish blood of Nicaragua". 


\section{REFERENCIAS}

Acuña Ortega, V. (2018). La formación del Estado en Nicaragua y Costa Rica en perspectiva comparada: Siglos XIX-XX. Anuario De Estudios Centroamericanos, 44, 247-285. Recuperado de https:// doi.org/10.15517/aeca.v44i0.34583

Acuña Ortega, V. H. (2005). Las concepciones de la comunidad política en Centroamérica en tiempos de la independencia, 1820-1823. En F. Colom González. (Ed.), Relatos de nación: La construcción de las identidades nacionales en el mundo hispánico, Tomo I (pp. 251-273). Madrid: Iberoamericana/Vervuert.

Ayala Benítez, L. E. (2007). La Iglesia y la Independencia de Centro América: El Caso de el Estado de El Salvador (1808-1833). Roma: Gregorian University Press.

Ayerdis, M. (2005). Publicaciones periódicas, formas de sociabilidad y procesos culturales en Nicaragua 1884-1926. Managua: Banco Central de Nicaragua.

Baldovinos, R. R. (Ed). (2000). Enciclopedia de El Salvador (Vol. 1). Barcelona: s.ed.

Barahona, A. (1989). Estudio sobre la historia de Nicaragua: del auge cafetalero al triunfo de la revolución. Managua: Editorial INIES.

Borgen, J. F. (1979). Una vida a la orilla de la historia: Memorias. Managua: DILESA.

Cardenal Tellería, M.A. (2000). Nicaragua y su historia: 1502-1936: cronología del acontecer histórico y construcción de la nación nicaragüense. Managua: Banco Mercantil.

Casáus Arzú, M. E. (2008) Das Überleben der Machteliten in Zentralamerika vom 16 bis zum 20 Jahrhundert. En S. Kurtenbach. et al. (Eds.), Zentralamerika heute. Politik,-Wirtschaft, Kultur (pp. 147-166). Frankfurt: Vervuert Verlag.

Cuadra Pasos, C. (1976). Obras. Vol 1. Managua: Colección Cultural Banco de America.

Díaz Arias, D. y Soto Quirós, R. (2007). Mestizaje, indígenas e identidad nacional en Centroámerica: de la Colonia a las Repúblicas Liberales (Cuadernos de Ciencias Sociales, $N^{\circ} .143$ ). San José, CR: FLACSO.

Dore, E. (2006). Myths of modernity: Peonage and Patriarchy in Nicaragua. Durham/London: Duke University Press.

Esgueva Gómez, A. (2000). Las constituciones políticas y sus reformas en la historia de Nicaragua. Tomo I. Managua: IHNCA-UCA.

Fry, M. F. (2008). Molina, Pedro. En Jay Kinsbruner y Erick D. Langer (Eds.), Encyclopedia of Latin American History and Culture ( $2^{\mathrm{a}}$ ed, pp. 654-655). Detroit: Gale.

Gobat, Michel. (2005). Confronting the American Dream: Nicaragua under U.S. Imperial Rule. Durham: Duke University Press. 
Gould, J. L. (1998). To Die in This Way: Nicaraguan Indians and the Myth of Mestizaje, 1880-1965. Durham: Duke Univ. Press.

Gould, J. L. (1993). »Vana Ilusión!« The Highlands Indians and the Myth of Nicaragua Mestiza, 18801925. The Hispanic American Historical Review, 73(3), 393-429.

Hall, C. y Pérez Brignoli, H. (2003). Historical Atlas of Central America. Norma: Univ. of Oklahoma Press.

Instrucción pública. (1841, noviembre 6). Mentor Nicaragüense. pp. 66-67. (http:// memoriacentroamericana.ihnca.edu.ni/uploads/media/18411106.pdf)

Kinloch Tijerino, F. (2004). Bajo la bota del imperio: 1910-1933. En M. Vannini (Dir.), Enciclopedia de Nicaragua (Vol. 1, pp. 129-137). Barcelona: Editorial Océano.

Kinloch Tijerino, F. (1990). "Cleto Ordóñez: Boceto biográfico de un caudillo popular". Revista de Historia, (1), 63-77.

Knight, F. W. (2008). Slavery in the Americas. En T. H. Holloway (Ed), A companion to Latin American History (pp. 146-161). Malden, MA: Blackwell.

Knight, F. (2000). The Haitian Revolution. The American Historical Review, 105(1), 104-105.

Lavrin, A. (1984). Women in Spanish America Colonial Society. En L. Bethell (Ed.), The Cambridge History of Latin America: Colonial Latin America (pp. 321-355). London: Cambridge University Press.

Levine, R. M. (1980). Race and Ethnic Relations in Latin America and the Caribbean: An Historical Dictionary and Bibliography. London: The Scarecrow Press.

Lockhart, J. (1984). Social Organization and Social Change in Colonial Spanish America. En L. Bethell (Ed.), The Cambridge History of Latin America: Colonial Latin America (Vol. 2, pp. 285-288). London: Cambridge University Press.

Luhmann, N. (1997). Die Gesellschaft der Gesellschaft (Vol. 2). Frankfurt: Shurkamp Verlag.

Luhmann, N. (1977). Differentiation of Society. The Canadian Journal of Sociology/Cahiers-canadiens de sociologie, 2(1), 29-53.

Martínez Peláez, S. (1998). La Patria del Criollo: Ensayo de interpretación de la realidad colonial guatemalteca. México, D.F.: Fondo de Cultura Económica.

Miranda Casij, E. (1972). La guerra olvidada» o la «guerra de los indios de 1881. Revista Conservadora del Pensamiento Centroamericano, 78(142), 75-82.

Molina, P. (1954) Escritos del Doctor Pedro Molina. El Editor Constitucional. Tomo Primero. Guatemala: Editorial del Ministerio de Educación Pública.

Molina, P. (1969). Escritos del Doctor Pedro Molina. Tomo II. (2a Ed). Guatemala: Editorial "José Pineda Ibarra". 
Moncada, J. M. (1932) Monografía histórica: El Presidente Moncada explica al pueblo nicaragüense sus ideas. Managua: Imprenta Nacional.

Montalván, J. H. (s.f.) Hace medio: Monografía Histórica. León: Imp. El CentroAmericano.

Núñez, O. (2006). La oligarquía en Nicaragua. Managua: CIPRES.

Romero Vargas, G. (1991). Las Estructuras sociales de Nicaragua en el siglo XVIII. Boletín Americanista, (41), 71.

Serrano, J. C. (1912). Acusaciones ante la Historia: El Partido Liberal al General Luis Mena, Ministro de la Guerra. Masaya: Tip. Colón.

Solórzano,J.C.(1990).Centroamérica a finales de la dominación Hispánica, 1750-1821:Transformación, Desarrollo y crisis de la sociedad colonial. Revista de Historia, (1), 37- 62.

The American Minister to the Secretary of State. American Legation, Managua (October 24, 1912). En United States Department of State. Papers relating to the Foreign Affairs of the United States with the annual message of the president transmitted to Congress December 3, 1912. Washington D.C.: Government Printing Office.

Tijerino, T. (1964). Reminiscencias históricas. Revista Conservadora, 7. (40), 6-54.

Torres-Rivas, E. (2011). Revoluciones sin cambios revolucionarios Ensayos sobre la crisis en Centroamérica. Ciudad de Guatemala: F\&G Editores.

del Valle, J. C. (1969). Escritos del Licenciado José Cecilio del Valle. Tomo Primero. Guatemala: Editorial "José Pineda Ibarra".

Weber, Max. (1922). Grundriss der Sozialökonomik III: Abteilung Wirtschaft und Gesellschaft. Tübingen: Verlag von J.C.B. Mohr.

Zavala, S. A. (1935). La Encomienda Indiana. Junta para Ampliación de Estudios e Investigaciones Científicas. Madrid: Imprenta Helénica.

Zeledón, B. (1977). Orden General del 10 de Agosto de 1912, dada en el Cuartel General de Tipitapa. En P. R. Gutiérrez. (Ed.), Partes de guerra del General Zeledón (pp. xx). Managua: Ediciones Lena. 